\title{
Molecular docking studies on quinazoline antifolate derivatives as human thymidylate synthase inhibitors
}

\author{
Vivek Srivastava ${ }^{1,4}$, Satya Prakash Gupta ${ }^{2}$, Mohd. Imran Siddiqi ${ }^{3}$ and Bhartendu Nath Mishra ${ }^{4 *}$ \\ ${ }^{1}$ Department of Biotechnology, Meerut Institute of Engineering \& Technology, Meerut-250005; ${ }^{2}$ Department of Pharmaceutical technology, \\ Meerut Institute of Engineering \& Technology, Meerut-250005 $5^{3}$ Computational Biology and Bioinformatics Lab., MSB Division, Central Drug \\ Research Institute; Lucknow- 226001; ${ }^{4}$ Department of Biotechnology, Institute of Engineering \& Technology, UP Technical University, Sitapur \\ Road, Lucknow 226021. Bhartendu Nath Mishra - E-mail: profbnmishra@gmail.com; Phone:+ 91-9415012030; + 91-522 - 2365730; \\ *Corresponding Author
}

Received October 30, 2009; Accepted November 15, 2009; Published February 28, 2010

\begin{abstract}
:
We have performed molecular docking on quinazoline antifolates complexed with human thymidylate synthase to gain insight into the structural preferences of these inhibitors. The study was conducted on a selected set of one hundred six compounds with variation in structure and activity. The structural analyses indicate that the coordinate bond interactions, the hydrogen bond interactions, the van der Waals interactions as well as the hydrophobic interactions between ligand and receptor are responsible simultaneously for the preference of inhibition and potency. In this study, fast flexible docking simulations were performed on quinazoline antifolates derivatives as human thymidylate synthase inhibitors. The results indicated that the quinazoline ring of the inhibitors forms hydrophobic contacts with Leu192, Leu221 and Tyr258 and stacking interaction is conserved in complex with the inhibitor and cofactor.
\end{abstract}

Keywords: Human thymidylate synthase, Quinazoline antifolate derivatives and Molecular docking.

\section{Background:}

Thymidylate synthase has been a primary target for chemotherapy aimed at cancers of the gastrointestinal tract and head and neck [1] despite moderate response in $30-40 \%$ of patients. Thymidylate synthase has been favorite target for designing and developing inhibitors which could be used as anticancer drugs [2]. A major problem affecting TS-directed treatments is that tumor cells often react to an exposure to Thymidylate synthase inhibitors by raising levels of intracellular TS activity about 2-to 4-fold, which may lead to resistance. Thymidylate synthase (TS) catalyzes the reductive methylation of 2'-deoxyuridine 5'-monophosphate (dUMP) to thymidine 5'-monophosphate (dTMP), using the co-substrate, 5,10methylenetetrahydrofolate $\left(\mathrm{CH}_{2} \mathrm{H}_{4}\right.$ folate $)$ as a one-carbon donor and reductant. The physical structures of bacterial TSs have been relatively well defined, and crystallographic data, in concert with data derived from kinetic, spectroscopic, and site-directed mutagenesis studies, have led to a detailed understanding of the catalytic mechanism of these enzymes [3]. In contrast, relatively few investigations of mammalian TS structure and catalysis have been conducted. The threedimensional structure of the native human thymidylate synthase (hTS) has been reported previously [4]. The data showed a surprising feature not observed in TSs from other sources: loop 181-197 containing the catalytic cysteine, Cys-195, was in an inactive conformation, and rotated $\sim 180^{\circ}$ with respect to its orientation in bacterial TSs, with the sulfhydryl of Cys-195 over $10 \AA$ from the location of sulfhydryls of corresponding cysteine residues in bacterial enzymes. Subsequent determination of the structure of a ternary inhibitory complex between closely related ratTS (rTS) and dUMP and tomudex [5] has shown that the ligands bind to the enzyme in the active conformation. Recently, it was found that also in the hTS.dUMP-tomudex complex hTS is in the active conformation. The inactive conformation has not been observed in TSs other than human [6].

Although T S does not represent a new target, there is still enthusiasm for the development of quinazoline derivatives. A unique feature of TS is the selectivity that is possible in the design of inhibitors. This makes it an ideal "old" target for rational and effective drug design for anticancer agents. Nowadays, molecular docking approaches are routinely used in modern drug design to help understand drug-receptor interaction. It has been shown in the literature that these computational techniques can strongly support and help the design of novel, more potent inhibitors by revealing the mechanism of drug--receptor

ISSN 0973-2063 (online) 0973-8894 (print)

Bioinformation 4(8): 357-365 (2010) interaction [7]. However, so far, there has been no report concerning the application of molecular docking methodology for understanding the binding of quinazoline antifolate derivatives. The antifolate compounds evaluated in this investigation are derivatives of quinazoline antifolate, having structures similar to the tomudex/ZD1694 class of antifolates, where quinazoline is a compound made up of two fused six-membered simple aromatic ring, a benzene ring and a pyrimidine ring. Its chemical formula is $\mathrm{C}_{8} \mathrm{H}_{6} \mathrm{~N}_{2}$. Due to an interest in new anticancer drugs, several quinazoline antifolate inhibitors were chosen from the ICI Pharmaceutical \& Institute of Cancer Research, England for screening against human thymidylate synthase [8-11].

Molecular docking is a key tool in structural molecular biology and computer-assisted drug design. The goal of ligand - protein docking is to predict the predominant binding model(s) of a ligand with a protein of known three-dimensional structure. In this study, we have used fast flexible docking to study the binding orientations and predict binding affinities of quinazoline antifolate derivatives. Such studies have been carried out to understand the forms of interaction of one hundred six compounds, sysnthesized by Marsham et al [8-11] for the human thymidylate synthase. The results obtained from this study would be useful in both understanding the inhibitory mode of quinazoline antifolate derivatives as well as in rapidly and accurately predicting the activities of newly designed inhibitors on the basis of docking scores. These models also provide some beneficial clues in structural modification for designing new inhibitors for the treatment of cancer with much higher inhibitory activities against thymidylate synthase.

\section{Methodology:}

\section{Molecular structures \& optimization}

The biological activity data of quinazoline antifolate derivatives (one hundred six compounds), reported by Marsham et al [8-11] was used in the present study shown in Table 1. The structures of all the compounds were constructed using the InsightII 2000.1 Builder module (http://www.accelrys.com). The geometries of these compounds were subsequently optimized using Discover module of InsightII 2000.1 using CVFF force field. The structure of humanTS protein (PDBid code 1I00) was obtained from Protein Data Bank (http://www.rcsb.org). 


\section{Bioinformation}

\section{Validation of the docking method}

To ensure that the ligand orientation and the position obtained from the docking studies were likely to represent valid and reasonable binding modes of the inhibitors, the LigandFit program docking parameters had to be first validated for the crystal structure used (PDBid 1I00). The ligand tomudex, in the conformation found in the crystal structure, was extracted and docked back to the corresponding binding pocket, to determine the ability of LigandFit to reproduce the orientation and position of the inhibitor observed in the crystal structure. Results of control docking showed that LigandFit determined the optimal orientation of the docked inhibitor, tomudex to be close to that of the original orientation found in the crystal shown in Figure 1(a). The low RMS deviation of $0.290 \AA$ between the docked and crystal ligand coordinates indicate very good alignment of the experimental and calculated positions especially considering the resolution of the crystal structure $(2.50 \AA)$.

Interaction modes between the quinazoline antifolate derivatives and human thymidylate synthase

To study the binding modes of quinazoline antifolate derivatives in the binding site of human thymidylate synthase, intermolecular flexible docking simulations were performed by means of LigandFit program and Dockscores were calculated from the docked conformations of the human thymidylate synthase-inhibitor complexes. All the compounds in the dataset were docked into the active site of human thymidylate synthase, using the same protocol. Thymidylate synthase monomer consists of an $\alpha / \beta$-fold containing $7 \alpha$-helices and $10 \beta$-strands, arranged in three layers : a six stranded mixed $\beta$-sheet, a long $\alpha$-helix across the sheet flanked by two shorter helices, and a mixed layer containing the remaining four helices and two antiparallel twostranded $\beta$-sheets. The large $\beta$-sheets from the monomers stack against each other to form dimer interface. The dimer contains two active sites, one within each monomer. The active site of human Thymidylate Synthase comprises of amino acids residues such as Arg50, Phe80, Leu 108, Asn112, Leu192, Asp218, Gly220, Leu221, Gly222, Phe225 and Tyr258. As most of the amino acid residues in the active site are hydrophobic so they are involved in strong hydrophobic interactions with the quinozoline antifolate derivatives. It was depicts the aligned binding conformations of the quinazoline antifolate derivatives in the binding pocket of the human thymidylate synthase, which were derived from the docking simulations by LigandFit software. Molecular docking studies of quinozoline antifolate derivatives into human thymidylate synthase binding site revealed very clear preference for the binding pocket. All of the inhibitors occupy the binding site well as seen from the Figure 2.

The majority of the contacts between the quinazoline antifolate derivatives and the protein are non polar, making use of the hydrophobic side chains in the binding site. Most of the quinazoline antifolate derivatives bind in more or less similar fashion with its quinazoline ring occupying the interior of the deep cleft and their tail is extended towards the entrance of the hydrophobic binding cavity. The quinazoline ring of quinazoline antifolate derivatives therefore bind to the human thymidylate synthase active site in an identical fashion, as reported in case of other inhibitors like tomudex [14] and raltitrexed [16]. The quinazoline ring of the inhibitors forms hydrophobic contacts with Leu192, Leu221 and Tyr258. As seen from our docking studies the quinozoline core occupies the same core in the binding site as does the quinazoline ring of tomudex and makes stacking interaction with pyrimidine ring of UMP. This stacking interaction is very important and has been conserved in all the thymidylate synthases for with crystal structures has been solved in complex with the inhibitor and cofactor. Figure 1(b) represents the binding conformations of the highly active compounds, all of which share the common binding mode with quinazoline core occupy space deep in the cavity and ester tail extends towards the solvent. 
The binding mode of the most active comp32 has been shown in Figure 1 (c). As expected, comp32 bind to the thymidylate synthase active site in the similar conformation as other known TS inhibitors (tomudex, ralitrexed etc.) which mainly bind using the quinazoline moiety and this moeity is presented to pyrimidine ring of cofactor UMP. This pterin ring is involved in $\pi-\pi$ stacking interactions with the pyrimidine ring of UMP. This stacking interaction is very important and has been conserved in most the thymidylate synthases for which crystal structures have been solved with UMP and inhibitors in ternary complex with the enzyme. The amino group substituted at quinazoline ring of comp32 makes significant hydrogen bonding interaction with side chain oxygen of Tyr258 and sugar oxygen atom of cofactor UMP. So it can be concluded that the presence of a hydrogen bond donor group at 2-position of the quinazoline moiety is important for thymidylate synthase activity of the inhibitors. In addition to this important hydrogen bonding interaction quinazoline ring nitrogen N3 and quinazoline carbonyl group make hydrogen bond with backbone oxygen of Asp218 and backbone nitrogen of Gly222 respectively. In addition to these hydrogen bonding interaction Comp32 is involved in van der Waals interactions through its phenyl ring with Ile108 and Phe225. Quinazoline ring is also involved in van der Waals interactions with the Trp109 (Residue not shown in figure for clarity) and Leu 221 of the protein. Phe 80 also show stacking interactions with the glutamyl chain of Comp32 and these particular interactions play very important role in thymidylate inhibition and need to be present for good inhibition by the inhibitors. Comp32 shows all the interactions shown by the well known potent inhibitor tomudex of thymidylate and binds in almost the same fashion as tomudex do, however comp32 show additional hydrogen bonding interaction via $\mathrm{NH}_{2}$ substituted at quinazoline moiety (Figure 1(c) instead of tomudex which has methyl group substituted at this position.

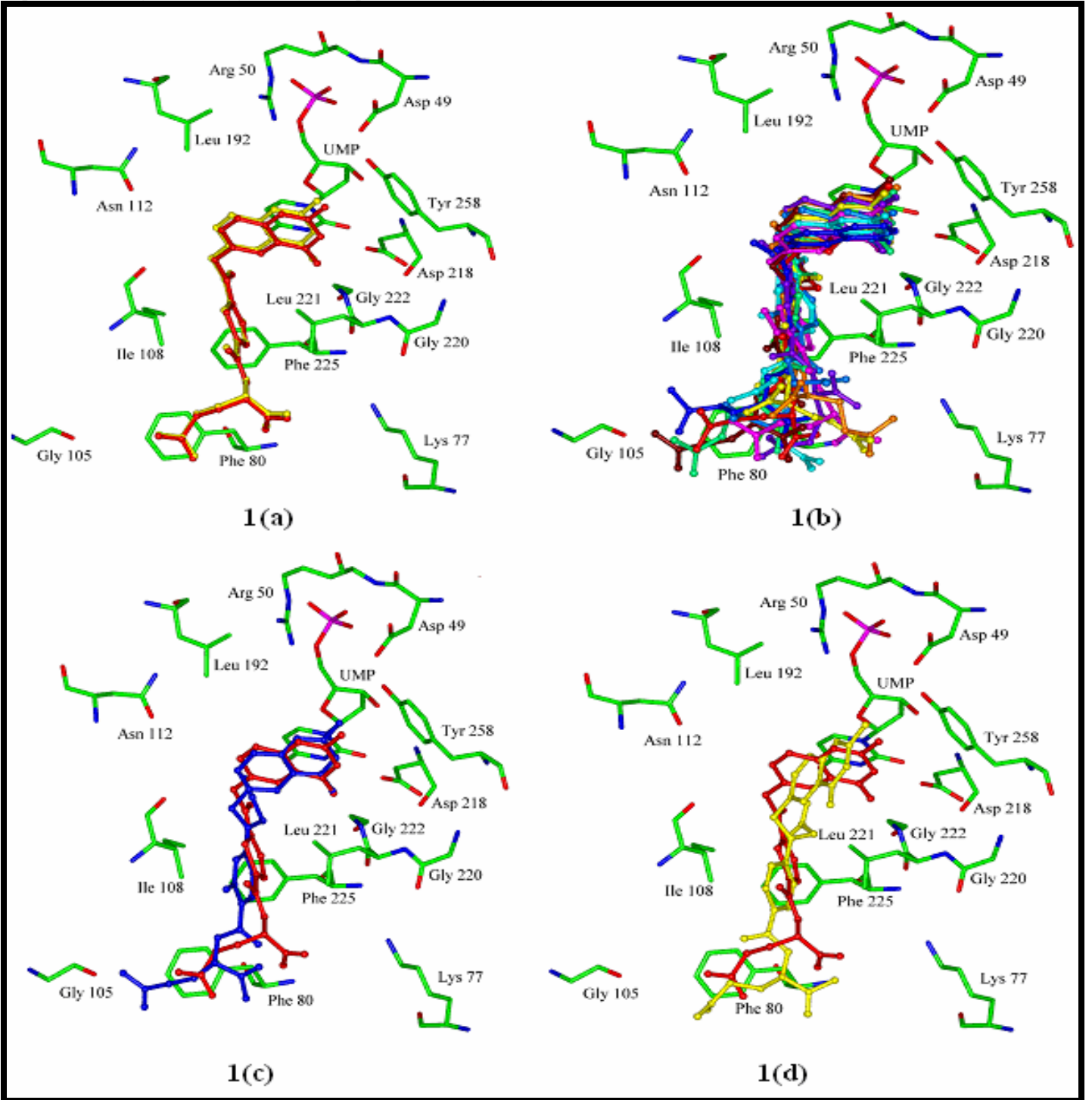

Figure 1: (a) Conformation of tomudex crystal structure (red) as compared to the docked conformation of tomudex (yellow) with cofactor substrate dUMP (atom color). Amino acid residues are presented by atom color, (b) Docked conformation highly active compounds (i) comp32 (brown) (ii) comp47 (red) (iii) comp31 (orange) (iv) comp35 (yellow) (v) comp1 (green blue) (vi) comp52 (cyan) (vii) comp50 (light blue) (viii) comp34 (blue) (ix) comp37 (violet) (x) comp76 (magenta), (c) Docked confirmation of comp32 compared with binding mode of tomudex, 1(d) Docked confirmation of comp13 compared with binding mode of tomudex and it shows the binding mode of least active comp13 and its comparison with the binding of tomudex. 


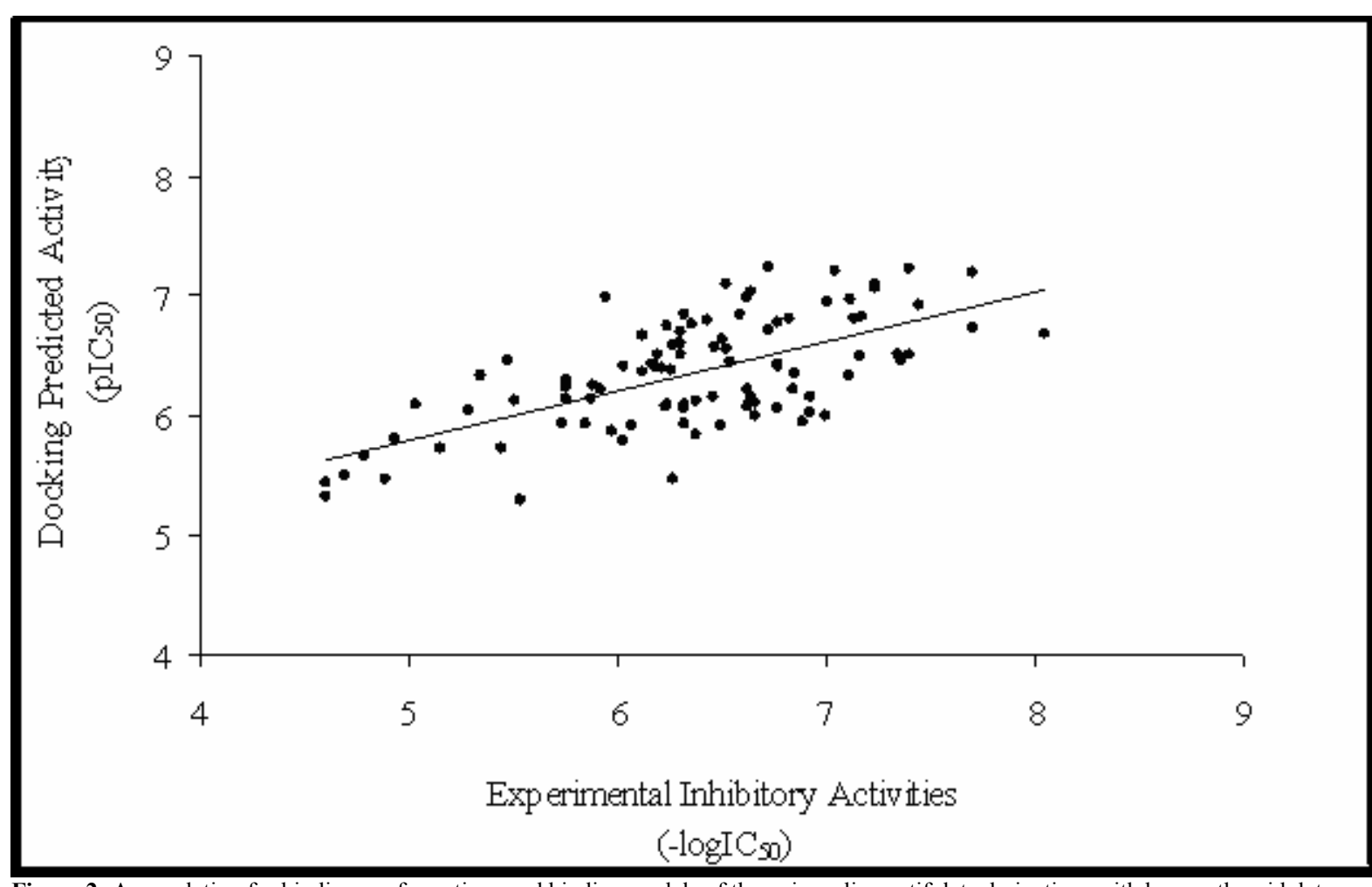

Figure 2: A correlation for binding conformations and binding models of the quinazoline antifolate derivatives with human thymidylate synthase.

Comp13 bind to thymidylate synthase active site in slightly tilted (about $45 \%$ ) way when compared to the binding of highly active comp32 and crystal structure ligand tomudex. This particular tilt in the binding may be contributed by the absence of the hydrogen bonding amino group substituted at 2-position of the quinazoline ring. Additionally, this hydrogen bond positions the inhibitors for stacking interactions with the pyrimidine ring of the cofactor UMP. Loss or decrease in the stacking interaction may lead to decreased affinity for the protein binding site. The phenyl ring in comp13 is unsubstituted whereas flourine atom is substituted at 3-position of highly active comp32 which may lead to decreased van der Waals interactions with Ile108 and Phe225 and hence lead to decreased activity in case of comp13 and other inactive compounds.

Correlation between docking scores and inhibitory activity An important application of LigandFit docking program in structurebased drug design is to predict the inhibitory activities while determining the binding conformation of an inhibitor with the target by making use of their dock scores. Linear regression analysis analyses were performed to explore whether the docking scores could be correlated with the experimental activities. The predicted inhibitory activity of quinazoline antifolate derivatives as inhibitors on the basis of dock score is listed in Table 1. Linear regression analysis analyses were performed to explore whether the docking scores could be correlated with the experimental activities. The equation was obtained for the inhibitory activities represented as $\mathrm{pIC}_{50}$ values, using the Dock score, Ligscore1, Ligscore2, -PLP1, -PLP2, JAIN, -PMF and Consensus score as the variable descriptors. A model with the correlation coefficient $\left(\mathrm{r}^{2}\right)$ of 0.148 was obtained for one hundred six compounds.Removal of 10 compounds (comp2, comp22, comp25, comp27, comp35, comp48, comp65, comp104, comp105, comp106) identified as outliers from the docking dataset yield a better model with correlation of coefficient $\left(\mathrm{r}^{2}\right)$ of 0.494 was obtained for ninety six compounds. This rather good correlation demonstrates that the binding conformations and binding models of the quinazoline antifolate derivatives with human thymidylate synthase are reasonable shown in Figure 2.

\section{Conclusion:}

The orientation of the quinazoline antifolate derivatives in the model complex is similar to that observed in the crystal structure. Despite some relaxation, due to the nature of the forcefield potentials, all important ligand-protein interactions are preserved during the energy minimization. Using the CVFF forcefield, the stacking interaction and hydrophobic contacts is very important in human thymidylate synthase complex with the quinazoline antifolate inhibitor and cofactor.

In this study, the molecular docking was applied to explore the binding mechanism and to correlate its docking score with the activity of a quinazoline antifolate derivatives. To our knowledge, this is the first study aimed at deriving docking studies for quinazoline antifolate derivatives. The docking studies provided good insights into the binding of quinazoline antifolate derivatives at the molecular level. Significant study between active sites and quinazoline antifolate derivatives will be analyzed to propose structural changes in these compounds, with the aim of rendering them more selective and thereby better human thymidylate synthase inhibitors.

\section{Acknowledgement:}

One of the authors, Mr. Vivek Srivastava is thankful to Council of Scientific and Industrial Research (CSIR), New Delhi for providing the Senior Research Fellowship (SRF) for carrying out the research work, Mr.Ashutosh Kumar for providing help in many ways for completion of this research work.

\section{References:}

[1] YM Rustum et al., J. Clin. Oncol. (1997) 15: 389 [PMID: 8996166]

[2] S Agrawal et al., J. Mol. Microbiol. Biotechnol. (2003) 6: 67 [PMID: 15044825]. 


\section{Bioinformation}

[3] CW Carreras et al., Annu. Rev. Biochem. (1995) 64: 721 [PMID: 7574499]

[4] CA Schiffer et al., Biochem. (1995) 34:16279.

[5] RR Sotelo-Mundo et al., Biochem. (1999) 38:1087.

[6] J Phan et al., Journal of Biolo. Chem. (2001) 276:14170.

[7] V Srivastava et al., Bioinformation (2008) 3: 180 [PMID: 19238244]

[8] LR Hughes et al., Journal of Med. Chem.(1990) 33: 3060.

[9] AL Jackman et al., Journal of Med. Chem. (1990) 33: 3067.
[10] PR Marsham et al., Journal of Med. Chem. (1990) 33: 3072.

[11] PR Marsham et al., Journal of Med. Chem. (1991) 34: 1594

[12] Cerius2 Version 4.10, Accelrys Inc., C. A. San Diego, http://www.accelrys.com.

[13] CM Venkatachalam et al., J. Mol. Graph Model (2003) 21: 289 [PMID: 12479928]

[14] R Almog et al., Protein Sci. (2001) 10: 988 [PMID: 11316879].

[15] PH Sayre et al., J.Mol.Biol. (2001) 313: 813 [PMID: 11697906].

[16] J Phan et al., Biochem. (2001) 40: 1897.

Edited by P. Kangueane Citation: Srivastava et al., Bioinformation, 4(8): 357-365 (2010) License statement: This is an open-access article, which permits unrestricted use, distribution, and reproduction in any medium, for noncommercial purposes, provided the original author and source are credited. 


\section{Supplementary material:}

Table 1: Quinazoline antifolate derivatives with modifications

Quinazoline antifolate derivatives with modifications

\begin{tabular}{|c|c|c|c|c|c|c|}
\hline Derivative & Position $\mathbf{R}^{1}$ & 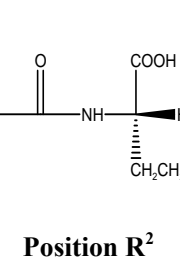 & $\begin{array}{c}\text { Experimental } \\
\text { Activity } \\
\left(\mathrm{pIC}_{50}\right)\end{array}$ & $\begin{array}{c}\text { Predicted } \\
\text { Activity } \\
\left(\mathrm{pIC}_{50}\right)\end{array}$ & Residual & $\begin{array}{c}\text { DOCK } \\
\text { SCORE }\end{array}$ \\
\hline Comp1 & $\mathrm{CH}_{3}$ & $\mathrm{CH}_{2} \mathrm{C} \equiv \mathrm{CH}$ & 7.398 & 7.223 & 0.175 & 62.0985 \\
\hline *Comp2 & $\mathrm{CH}_{3}$ & $\mathbf{H}$ & 5.35 & $* * * * * * * * * *$ & $* * * * * * * * *$ & $* * * * * * * * *$ \\
\hline Comp3 & $\mathrm{CH}_{3}$ & $\mathrm{CH}_{3}$ & 6.523 & 6.554 & -0.031 & 74.1296 \\
\hline Comp4 & $\mathrm{CH}_{3}$ & $\mathrm{CH}_{2} \mathrm{CH}_{3}$ & 6.77 & 6.417 & 0.353 & 70.5759 \\
\hline Comp5 & $\mathrm{CH}_{3}$ & $\mathrm{CH}_{2} \mathrm{CH}=\mathrm{CH}_{2}$ & 6.319 & 6.848 & -0.529 & 54.0339 \\
\hline Comp6 & $\mathrm{CH}_{3}$ & $\left(\mathrm{CH}_{2}\right)_{2} \mathrm{~F}$ & 6.62 & 6.218 & 0.402 & 40.9059 \\
\hline Comp7 & $\mathrm{CH}_{3}$ & $\left(\mathrm{CH}_{2}\right)_{2} \mathrm{Br}$ & 5.886 & 6.260 & -0.374 & 55.3321 \\
\hline Comp8 & $\mathrm{CH}_{3}$ & $\left(\mathrm{CH}_{2}\right)_{2} \mathrm{SH}$ & 5.754 & 6.261 & -0.507 & 49.5824 \\
\hline Comp9 & $\mathrm{CH}_{3}$ & $\left(\mathrm{CH}_{2}\right)_{2} \mathrm{OH}$ & 6.301 & 6.598 & -0.297 & 79.1328 \\
\hline Comp10 & $\mathrm{CH}_{3}$ & $\left(\mathrm{CH}_{2}\right)_{3} \mathrm{OH}$ & 6.268 & 5.477 & 0.791 & 34.8098 \\
\hline Comp11 & $\mathrm{CH}_{3}$ & $\left(\mathrm{CH}_{2}\right)_{2} \mathrm{OCH}_{3}$ & 4.789 & 5.661 & -0.872 & 61.0809 \\
\hline Comp12 & $\mathrm{CH}_{3}$ & $\left(\mathrm{CH}_{2}\right)_{3} \mathrm{OCH}_{3}$ & 4.889 & 5.471 & -0.582 & 41.3214 \\
\hline Comp13 & $\mathrm{CH}_{3}$ & $\mathrm{CH}_{2} \mathrm{COCH}_{3}$ & 4.602 & 5.437 & -0.835 & 42.7647 \\
\hline Comp14 & $\mathrm{CH}_{2} \mathrm{CH}_{3}$ & $\mathrm{CH}_{2} \mathrm{C} \equiv \mathrm{CH}$ & 6.854 & 6.353 & 0.501 & 56.3263 \\
\hline Comp15 & $\mathrm{CH}_{2} \mathrm{CH}_{3}$ & $\mathrm{H}$ & 4.699 & 5.504 & -0.805 & 69.3533 \\
\hline Comp16 & $\mathrm{CH}\left(\mathrm{CH}_{3}\right)_{2}$ & $\mathrm{CH}_{2} \mathrm{C} \equiv \mathrm{CH}$ & 6.208 & 6.394 & -0.186 & 50.3742 \\
\hline Comp17 & $\mathrm{CH}_{2} \mathrm{~F}$ & $\mathrm{CH}_{2} \mathrm{C} \equiv \mathrm{CH}$ & 7.0 & 6.004 & 0.996 & 54.8555 \\
\hline Comp18 & $\mathrm{CH}_{2} \mathrm{~F}$ & $\mathrm{CH}_{3}$ & 5.535 & 5.297 & 0.238 & 56.1197 \\
\hline Comp19 & $\mathrm{CH}_{2} \mathrm{~F}$ & $\mathrm{CH}_{2} \mathrm{CH}_{3}$ & 6.432 & 6.801 & -0.369 & 64.1659 \\
\hline Comp20 & $\mathrm{CH}_{2} \mathrm{~F}$ & $\left(\mathrm{CH}_{2}\right)_{2} \mathrm{~F}$ & 6.469 & 6.573 & -0.104 & 59.3171 \\
\hline Comp21 & $\mathrm{CH}_{2} \mathrm{~F}$ & $\mathrm{CH}_{2} \mathrm{C} \equiv \mathrm{CH}$ & 6.237 & 6.744 & -0.507 & 59.1139 \\
\hline *Comp22 & $\mathbf{C F}_{3}$ & $\mathrm{CH}_{2} \mathrm{C} \equiv \mathrm{CH}$ & 5.24 & $* * * * * * * * * *$ & $* * * * * * * * *$ & $* * * * * * * * *$ \\
\hline Comp23 & $\mathrm{CH}_{2} \mathrm{OH}$ & $\mathrm{CH}_{3}$ & 6.194 & 6.512 & -0.318 & 62.7282 \\
\hline Comp24 & $\mathrm{CH}_{2} \mathrm{OH}$ & $\mathrm{CH}_{2} \mathrm{CH}_{3}$ & 6.585 & 6.836 & -0.251 & 50.1905 \\
\hline *Comp25 & $\mathrm{CH}_{2} \mathrm{OH}$ & $\mathrm{CH}_{2} \mathrm{CH}=\mathrm{CH}_{2}$ & 6.04 & $* * * * * * * * * *$ & $* * * * * * * * *$ & $* * * * * * * * *$ \\
\hline Comp26 & $\mathrm{CH}_{2} \mathrm{OH}$ & $\left(\mathrm{CH}_{2}\right)_{2} \mathrm{~F}$ & 6.658 & 6.113 & 0.545 & 58.132 \\
\hline *Comp27 & $\mathrm{CH}_{2} \mathrm{OH}$ & $\left(\mathrm{CH}_{2}\right)_{2} \mathrm{OH}$ & 6.11 & $* * * * * * * * * *$ & $* * * * * * * * *$ & $* * * * * * * * *$ \\
\hline Comp28 & $\mathrm{CH}_{2} \mathrm{NHCOCH}_{3}$ & $\mathrm{CH}_{2} \mathrm{C} \equiv \mathrm{CH}$ & 6.319 & 6.057 & 0.262 & 68.6361 \\
\hline Comp29 & $\mathrm{CH}_{2} \mathrm{~S}$-2-pyrimidine & $\mathrm{CH}_{2} \mathrm{C} \equiv \mathrm{CH}$ & 6.62 & 6.990 & -0.370 & 16.4223 \\
\hline Comp30 & Phenyl & $\mathrm{CH}_{2} \mathrm{C} \equiv \mathrm{CH}$ & 6.658 & 5.994 & 0.664 & 44.0336 \\
\hline
\end{tabular}




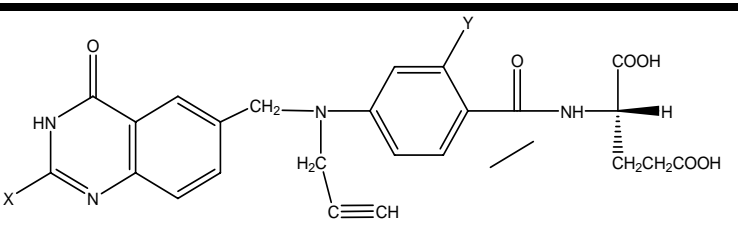

Position X Position Y

Comp31

Comp32

Comp33

Comp34

*Comp35

Comp36

Comp37

Comp38

Comp39

Comp39

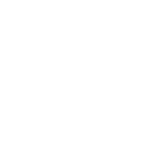

Comp40

Comp41

Comp42

Comp43

Comp44

Comp45

Comp46

Comp47

*Comp48

Comp49

Comp50

Comp51

Comp52

Comp53

Comp54

Comp55

Comp56

Comp57

Comp58

Comp59

Comp60<smiles>Cc1ccc2nc(C)[nH]c(=O)c2c1</smiles>

Position X

\begin{abstract}
$\mathrm{H}$
\end{abstract}
H

$\mathrm{H}$

$\mathrm{H}$

H

$\mathrm{H}$

$\mathrm{H}$

2'- F

2'- F

2'- F

2'- F

$2^{\prime}-\mathrm{F}$

2'- F

$2^{\prime}-F$

2'- F

$2^{\prime}-\mathrm{F}$

$2^{\prime}-F$

2'- F

$3-F$

$3-F$

3'- F

\section{$\mathrm{H}$}

F

H

F

F

H

F

H

$\mathrm{F}$
7.699

8.046

6.77

7.237

7.7

7.009

7.237

7.167

7.444

$$
\begin{aligned}
& 6.729 \\
& 6.686 \\
& 6.784 \\
& 7.100
\end{aligned}
$$

$* * * * * * * * *$

6.959

7.063

6.498

6.929

\subsection{0}

1.360

$-0.014$

0.137

$* * * * * * * * *$

0.050

0.174

0.669

0.515
76.5712

70.4486

51.1791

70.4062

$* * * * * * * * *$

63.9713

65.219

71.557

55.4344

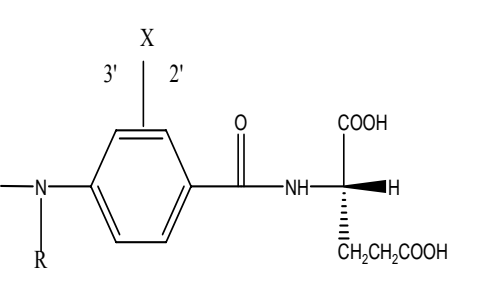

Position R

ISSN 0973-2063 (online) 0973-8894 (print)

5.347

6.523

$\mathrm{CH}_{2} \mathrm{CH}_{3}$

$\mathrm{CH}_{2} \mathrm{CH}=\mathrm{CH}_{2}$

$\left(\mathrm{CH}_{2}\right)_{2} \mathrm{~F}$

$\left(\mathrm{CH}_{2}\right)_{2} \mathrm{OH}$

$\left(\mathrm{CH}_{2}\right)_{3} \mathrm{OH}$

$\mathrm{CH}_{2} \mathrm{C} \equiv \mathrm{CH}$

\section{H}

$\mathrm{CH}_{3}$

$\mathrm{CH}_{2} \mathrm{CH}_{3}$

$\mathrm{CH}_{2} \mathrm{CH}=\mathrm{CH}_{2}$

$\left(\mathrm{CH}_{2}\right) \mathrm{F}$

$\left(\mathrm{CH}_{2}\right)_{2} \mathrm{OH}$

$\left(\mathrm{CH}_{2}\right)_{3} \mathrm{OH}$

$\left(\mathrm{CH}_{2}\right)_{2} \mathrm{NH}_{2}$

$\mathrm{CH}_{2} \mathrm{CN}$

$\mathrm{CH}_{2} \mathrm{CONH}_{2}$

$\mathrm{CH}_{2} \mathrm{C} \equiv \mathrm{CH}$

$\mathrm{H}$

$\mathrm{CH}_{3}$
6.77

6.319

6.62

6.301

6.268

7.699

5.42

6.921

7.347

7.119

7.367

7.108

6.229

4.931

6.77

5.873

5.845

5.03

5.943

$$
\begin{aligned}
& 6.337 \\
& 7.106 \\
& 6.428 \\
& 6.091 \\
& 6.070 \\
& 6.703 \\
& 6.591 \\
& 7.199
\end{aligned}
$$

$* * * * * * * * *$

6.160

6.503

6.965

6.464

6.328

6.074

5.808

6.058

6.144

5.933

6.085

6.991

$\begin{array}{cc}-0.990 & 77.7392 \\ -0.583 & 61.9592 \\ 0.342 & 56.3273 \\ 0.228 & 69.6427 \\ 0.550 & 49.2357 \\ -0.402 & 56.3914 \\ -0.323 & 48.7268 \\ 0.500 & 60.0104 \\ * * * * * * * * * & * * * * * * * * *\end{array}$$$
0.761
$$

77.1705

$0.844 \quad 70.4267$

0.154

41.9114

0.903

60.3416

0.780

62.0603

0.155

53.2662

$-0.877$

57.7233

0.712

53.4187

$-0.271$

62.2975

$-0.088$

42.5697

$-1.055$

66.332

$-1.048$

65.3901 


\section{Bioinformation}

\begin{tabular}{|c|c|c|c|c|c|c|}
\hline Comp61 & $3-F$ & $\mathrm{CH}_{2} \mathrm{CH}_{3}$ & 6.167 & 6.425 & -0.258 & 60.914 \\
\hline Comp62 & $3-F$ & $\mathrm{CH}_{2} \mathrm{CH}=\mathrm{CH}_{2}$ & 5.287 & 6.050 & -0.763 & 55.0781 \\
\hline Comp63 & $3-F$ & $\left(\mathrm{CH}_{2}\right)_{2} \mathrm{~F}$ & 5.757 & 6.293 & -0.536 & 59.9575 \\
\hline Comp64 & $3 ’-F$ & $\left(\mathrm{CH}_{2}\right)_{2} \mathrm{OH}$ & 5.446 & 5.729 & -0.283 & 55.404 \\
\hline *Comp65 & $3-F$ & $\left(\mathrm{CH}_{2}\right)_{3} \mathrm{OH}$ & 6.01 & $* * * * * * * * *$ & $* * * * * * * * *$ & $* * * * * * * * *$ \\
\hline Comp66 & $2^{\prime}-\mathrm{Cl}$ & $\mathrm{CH}_{2} \mathrm{C} \equiv \mathrm{CH}$ & 7.131 & 6.818 & 0.313 & 59.7118 \\
\hline Comp67 & $2^{\prime}-\mathrm{Cl}$ & $\mathrm{CH}_{2} \mathrm{CH}_{3}$ & 6.921 & 6.024 & 0.897 & 57.9843 \\
\hline Comp68 & $2-\mathrm{CF}_{3}$ & $\mathrm{CH}_{2} \mathrm{C} \equiv \mathrm{CH}$ & 6.319 & 5.928 & 0.391 & 53.5381 \\
\hline Comp69 & $2^{\prime}-\mathrm{CH}_{3}$ & $\mathrm{CH}_{2} \mathrm{C} \equiv \mathrm{CH}$ & 6.301 & 6.513 & -0.212 & 72.9112 \\
\hline Comp70 & $2^{\prime}-\mathrm{CH}_{3}$ & $\mathrm{CH}_{3}$ & 6.027 & 6.416 & -0.389 & 65.5774 \\
\hline Comp71 & $2^{\prime}-\mathrm{CH}_{3}$ & $\mathrm{CH}_{2} \mathrm{CH}_{3}$ & 6.495 & 5.912 & 0.583 & 56.4926 \\
\hline Comp72 & 2'- $\mathrm{NH}_{2}$ & $\mathrm{CH}_{2} \mathrm{C} \equiv \mathrm{CH}$ & 6.538 & 6.437 & 0.101 & 61.8012 \\
\hline Comp73 & $2^{\prime}-\mathrm{NH}_{2}$ & $\mathrm{CH}_{3}$ & 6.066 & 5.913 & 0.153 & 74.1392 \\
\hline Comp74 & $2^{\prime}-\mathrm{NH}_{2}$ & $\mathrm{CH}_{2} \mathrm{CH}_{3}$ & 6.509 & 6.634 & -0.125 & 67.3791 \\
\hline Comp75 & $2-\mathrm{OH}$ & $\mathrm{CH}_{2} \mathrm{C} \equiv \mathrm{CH}$ & 7.046 & 7.218 & -0.172 & 79.6766 \\
\hline Comp76 & $2-\mathrm{OCH}_{3}$ & $\mathrm{CH}_{2} \mathrm{C} \equiv \mathrm{CH}$ & 7.174 & 6.829 & 0.345 & 63.4102 \\
\hline Comp77 & $2^{\prime}-\mathrm{OCH}_{3}$ & $\mathrm{CH}_{2} \mathrm{CH}_{3}$ & 6.721 & 7.250 & -0.529 & 55.2489 \\
\hline Comp78 & $2-\mathrm{NO}_{2}$ & $\mathrm{CH}_{2} \mathrm{C} \equiv \mathrm{CH}$ & 6.886 & 5.945 & 0.941 & 52.9612 \\
\hline \multirow[t]{2}{*}{ Comp79 } & $2-\mathrm{NO}_{2}$ & $\mathrm{CH}_{2} \mathrm{CH}_{3}$ & 6.84 & 6.226 & 0.613 & 47.4045 \\
\hline & Position R & Position Ar & & & & \\
\hline Comp80 & $\mathrm{CH}_{2} \mathrm{C} \equiv \mathrm{CH}$ & & 6.357 & 6.757 & -0.400 & 54.2254 \\
\hline Comp81 & $\mathrm{H}$ & & 4.606 & 5.323 & -0.717 & 69.7193 \\
\hline Comp82 & $\mathrm{CH}_{3}$ & & 6.174 & 6.413 & -0.239 & 88.1727 \\
\hline Comp83 & $\mathrm{CH}_{2} \mathrm{CH}_{3}$ & & 6.237 & 6.089 & 0.148 & 65.42 \\
\hline Comp84 & $\left(\mathrm{CH}_{2}\right)_{2} \mathrm{CH}_{3}$ & & 5.733 & 5.928 & -0.195 & 27.2274 \\
\hline Comp85 & $\mathrm{CH}_{2} \mathrm{CH}=\mathrm{CH}$ & & 5.755 & 6.137 & -0.382 & 57.8916 \\
\hline Comp86 & $\left(\mathrm{CH}_{2}\right)_{2} \mathrm{~F}$ & & 6.26 & 6.377 & -0.117 & 58.3581 \\
\hline Comp87 & $\left(\mathrm{CH}_{2}\right)_{2} \mathrm{OH}$ & & 5.921 & 6.227 & -0.306 & 68.9653 \\
\hline
\end{tabular}




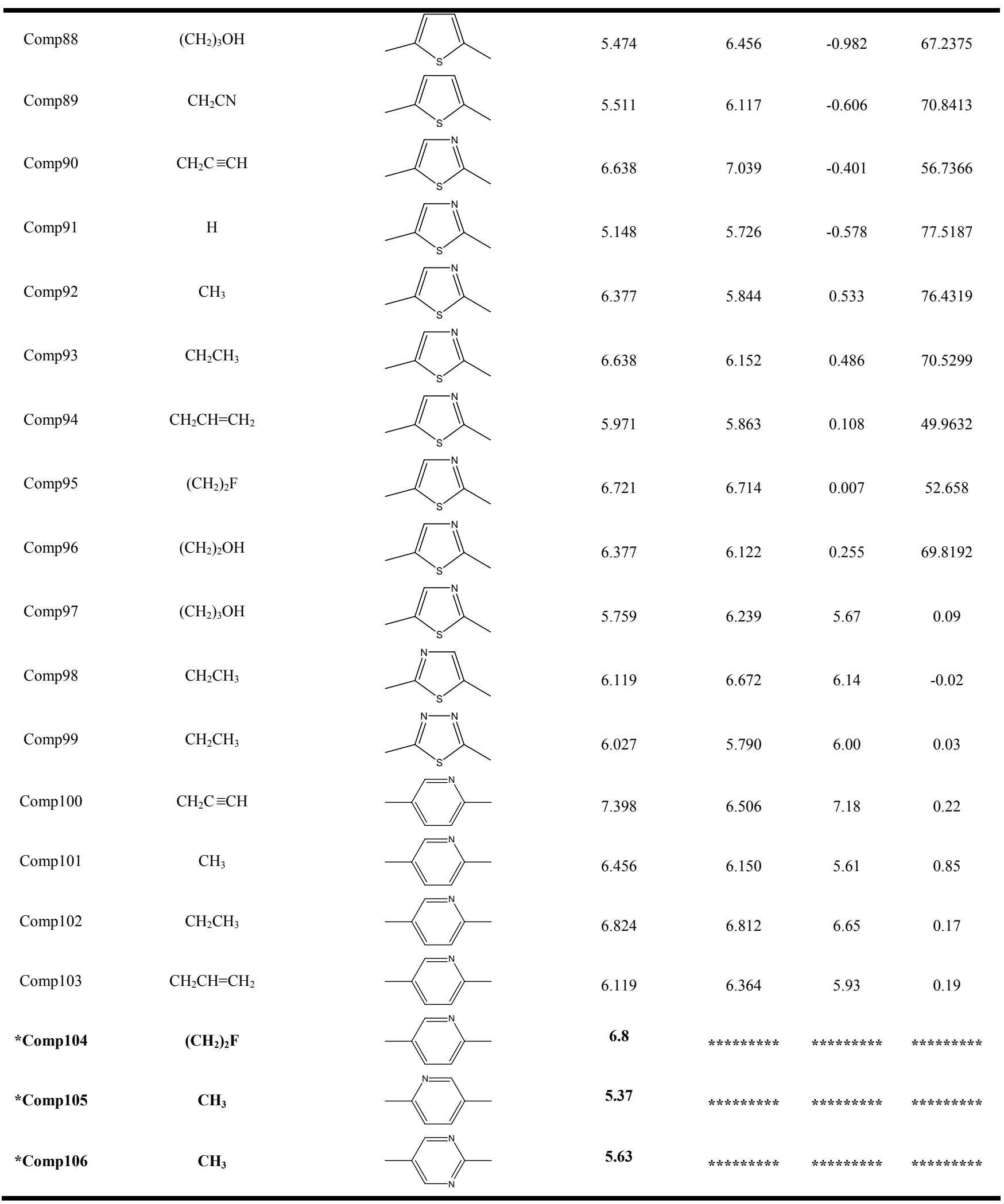

